\title{
How valuable is the student grant?
}

from Richard Pearson

\section{The student grant in the United Kingdom has been severely devalued by the effects of inflation. But individual circumstances vary widely.}

ALThough graduate employment prospects are improving rapidly from the doldrums of the early 1980 s, many will still not find an easy or speedy transition from higher education into employment (Nature $310,260 ; 1984)$. With the government and its critics continuing to debate the likely level of future demand for places in the light of the declining numbers of 18-yearolds in the population, and with the apparent falling "rate of return" to studying many subjects in higher education, how attractive is the student grant in terms of supporting three years' investment in higher education?

In order to encourage student interest in subjects in demand by employers, the UK Department of Education and Science has announced that the amount undergraduates can receive from a sponsoring employer before their grant is affected will rise to $£ 1,200$ together with a $£ 400$ earnings allowance. For the lucky few who can combine sponsorship (see Nature 307, 488; 1984) with a full grant, this means a student income of nearly $£ 3,500$ for the academic year, double the basic grant. A recent survey for the National Union of Students (Undergraduate Income and Expenditure, NUS, 1984) has, however, shown that for most students half this figure may be unattainable, with many parents not making up their means-tested contribution. Although the basic grant in 1982-83 was $£ 1,595$, the average student received only $£ 1,167$, and there has been growing concern about the adequacy of this grant whose value has fallen behind the inflation rate over the past few years.

In the United Kingdom, grants are payable to the majority of students on a means-tested basis; a student living away from home at a college outside London in 1982-83 could have received a maximum grant of $£ 1,595$ plus tuition fees from his local education authority. Various supplements are also payable, for example, to those studying in London, or on a course that is longer than normal, while mature students receive a full grant with no means test. One in eight students, however, received only the minimum grant payable of $f 410$, some because they, or their parents, refused to take the means test, while a further 5 per cent received less than $£ 600$ because their parental income was too high. Half received under $£ 1,200$ and only one in four students received the maximum grant. The total amount saved by the means test was estimated to be over $£ 150$ million in 1982-83 compared with a total

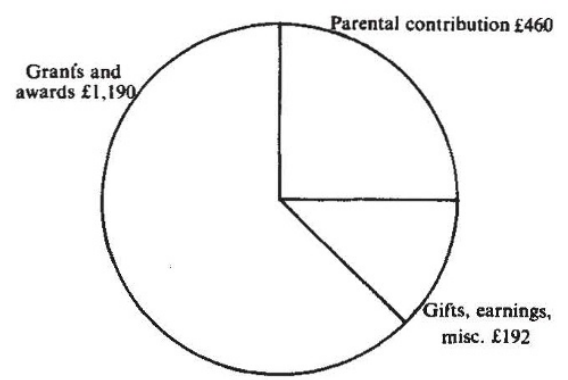

Fig. 1 Sources of student income for UK university and polytechnic students in 1982-83. (Source: NUS survey).

public expenditure on grants of about $£ 500$ million. Just over half the parents paid their assessed contribution, a rather higher proportion than in 1974-75 when only just over a quarter did so. Interestingly almost as many parents paid more than the assessed contribution as paid less than the total due and the size of the sum due from parents did not seem to affect the likelihood of the student receiving more or less than that assessed. In terms of basic grant, science and social science students got slightly higher amounts than the engineers and arts students. Average income for the academic year, including additions such as gifts and term-time earnings was $£ 1,842$, two thirds coming from the basic grant (Fig. 1).

A significant additional source of student income, outside term time, was vacation jobs, which gave an average income of $£ 251$ per student, with 10 per cent earning in excess of $£ 700$, and a few earning over $£ 200$ per week, although nearly half had no vacation job. By contrast ten years earlier 80 per cent of students had vacation jobs in the summer. Men received rather higher vacation income than women, while engineers and technology students received significantly more than the average, aided by sponsorship and enhanced prospects of vacation work. This latter factor also boosted termtime incomes of these students. Supplementary benefit and vacation grants were further sources of income out of term time for a minority of students, the average sum overall being around $£ 100$ per student.

Where then does the money go? Accommodation is the biggest outgoing. Only one in ten undergraduates in the United Kingdom lives in the parental home, while nearly half live in "official"' college halls or hostels. College premises are particularly important for university students while for those at polytechnics, rented flats were the

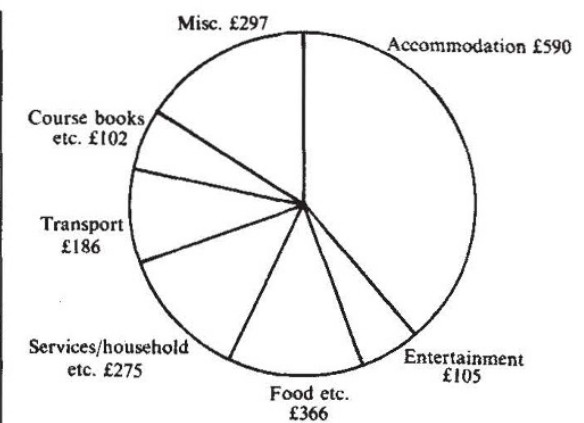

Fig. 2 Student expenditure for the academic year 1982-83. (Source: NUS survey).

most common form of accommodation. In London, more students live in their parents' home because of easier travel conditions and larger college catchment areas and the lower availability of halls of residence. The average cost of college accommodation was $£ 24$ per week, with the polytechnics cheaper than the universities, most college accommodation including some food and services. Those in private rented accommodation paid an average of $£ 14$ per week each for rent alone.

Other living costs included food and household expenses, travel and recreational. Course-related expenditure included books and course equipment; average annual expenditure was to be around $£ 100$ with university students spending most (Fig. 2) and 10 per cent apparently spending nothing at all on books. On a subject basis, medical students spent most on course equipment with social science and language students also spending above the average.

The study showed that the majority of students relied on parental support or supplementary income to support part of their studies. While for the "average" student such supplementary income was usually forthcoming, some receiving more than the notionally required sum, many had to restrict expenditure significantly to sustain themselves. The survey, by revealing the many sources of income and grants available and the various patterns of expenditure, highlights the complexities of an informed debate about student finance. Perhaps the one clear message that comes through is that to plan grants, loans and finance around a notional average case will lead to very different outcomes for different individuals. Student finance is not an exact science.

Richard Pearson is at the Institute of Manpower Studies, Mantell Building, University of Sussex, Brighton BNI 9RF, UK. 